\title{
Advantage analysis of aluminum honeycomb composite used in motorhomes
}

\author{
Xinghai Shao ${ }^{1, a}$, Qianqian Yang ${ }^{1,2}$, Yuan Liu $^{3}$ and Lei Cao ${ }^{1,2}$ \\ ${ }^{1}$ Luoyang Advanced Manufacturing Industrial R\&D Center, Tianjin Research Institute for Advanced Equipment, Tsinghua University, \\ Luoyang 471004, China \\ ${ }^{2}$ Qingyan Tecai technology (Luoyang) Co., Ltd, Luoyang 471004, China \\ ${ }^{3}$ Tsinghua University, Beijing 100083, China
}

\begin{abstract}
In the light weight, high weather resistance and environmental protection requirements of the panel used for the motorhome, aluminum honeycomb composite, as a new material with mature industrialization and excellent performance, has a good application prospect in the quality improvement and material upgrading of the panel used for the motorhome. In this paper, the existing problems of the panel used for the motorhome and the properties of aluminum honeycomb composite are discussed, the advantages of applying aluminum honeycomb composite to the board of the motorhome are analyzed. The application of aluminum honeycomb composite materials to motorhomes will meet the requirements for improving the quality of panels , such as reduced in weight, environmentally friendly, non-combustible, recyclable, improved weather resistance and increased service life.
\end{abstract}

\section{Introduction}

The sample survey of China tourist vehicle and Vessel Association shows that, in 2020, China's self-driving travel group still reached 2 billion 240 million passengers under the influence of the new crown pneumonia epidemic, and the scale of self driving travel industry market was 125 billion 300 million RMB, up 10.4\% from the same period last year ${ }^{1]}$. With the normalization of epidemic prevention and control, and the growing demand for self driving travel, China's motorhome industry has ushered in the spring of rapid development, and the prospect is worth looking forward to.

Along with the development comes product upgrading and market competition. To a certain extent, the competition of the current motorhome industry is mainly distributed among product design, product material quality and reliability. For example, the lightweight, costeffective, weatherability, environmental protection and fire resistance of the panel used in the passenger compartment are the necessary conditions for the passenger compartment to remain invincible in the market competition. In the demand of high-quality motorhome, aluminum honeycomb composite materials and panels with outstanding advantages, have excellent lightweight, cost-effective and environmental protection characteristics, and have good application prospects in the upgrading of compartment materials. Especially in the process of vigorously promoting the key parts technology autonomy, it is urgent to develop and master the highquality panel manufacturing technology of light weight, weather resistance and environmental protection for residential vehicles. The lightweight and durable aluminum honeycomb composite materials and technology are widely used in the material upgrading of the panel of the motorhomes, which meets the development and application needs of the lightweight composite materials in the high-tech field ${ }^{[2-4]}$.

\section{Page layout}

In vehicles, there are many kinds and quantities of panels used in motorhome, mainly including exterior compartment panel and interior furniture panel. At present, the main materials for the panel used in the motorhome are metal panels, polymer foam composite panels and wood panels. Based on the actual use environment of vehicles stored and walking in the open air, there are some requirements for the panels used in the motorhome, such as weight reduction, environmental protection, incombustibility, recyclability, weatherability improvement and service life improvement.

The main components and key components of the motorhome are compartment and interior furniture. By taking the materials and their preparation process used by a Chinese motorhome joint venture company as an example, the problems and demands for quality improvement of existing panels are analyzed. The company used a German production line, mainly produces European models of motorhome. According to the quality requirements of the vehicle, all carriage panels were imported. The following is a comparative analysis of the existing technology and service life of the carriage panel.

$\overline{{ }^{a} \text { Xinghai Shao: shaoxh@lamic.com.cn }}$ 


\subsection{Existing technology and problems of carriage panel}

The panel for the motorhome mainly includes the panel for the outer wall of the carriage and the panel for the interior furniture, including the panel for the outer wall covering six sides of the carriage and the door panel, bed panel and cabinet panel for the interior furniture. Environmental protection, light weight, weathering resistance, aging resistance and UV resistance are important indicators of the panel. The general requirements of the composite panel are to meet the requirements of $60-70{ }^{\circ} \mathrm{C}$ and comply with the environmental protection standard. The company's panels are all imported materials. In the domestic market, more than $5 \%$ of the imported materials and $95 \%$ of the domestic panels are used in a comprehensive way. The advantages of the imported panels in appearance quality and service life are much higher than those of the domestic panels.

The following is an example to illustrate the problems existing in the current vehicle panel and the gap with foreign technology. Most of the carriage panels are composite structures, which are divided into panel core and panel veneer.

(1) Comparison from the material: (1)The imported carriage panel adopts $3 \mathrm{~mm}$ veneer + insulation layer +2 $3 \mathrm{~mm}$ PVC material. The insulation layer material of the core is composed of two kinds of polymer composite materials with different hardness, which are used for structural strengthening and filling respectively. The insulation material can be recycled. The veneer of imported panel can be made of different materials, such as metal, wood and PVC, and the veneer is generally not recyclable. (2) The core filling material of domestic panel is ordinary thermal insulation material with small thickness. The inner veneer uses rolled metal veneer instead of PVC layer, so as to reduce the production cost, but the quality of panel decreases.

(2) In terms of service life, the domestic panels are generally $30-50 \mathrm{~mm}$ thick. At present, the main problems are short service life and poor weather resistance, and even easy to blister and seep after one year of use. The total thickness of the imported panel is about $50 \mathrm{~mm}$, and its service life is generally 8 years.

(3) In terms of technology, there are two kinds of composite methods: positive spinning and vacuum negative pressure rolling. The former has poor surface quality but high bonding strength, while the latter has good surface quality but easy peeling. In addition to rolling veneer, color aluminum veneer is also used in a small amount of composite panel. At present, due to less application and immature technology, rolled veneer and color aluminum panel are difficult to repair. In comparison, PVC is easier to repair. But in the future, with the popularization and application of metal panel in motorhome and the development of repair technology, this problem will be gradually improved.

Generally speaking, the main problem of the current domestic panel used in the motorhome is poor weather resistance, and the advantage is low cost, which is mainly used as low-end panel; The imported panel has good weather resistance, but the cost is very high, so it is often used as high-end panel. The furniture panel of the motorhome is mainly composite panel. Like the composite panel used in the carriage, there is also a big difference in quality between home and abroad. The high-end furniture panel is generally imported.

\subsection{Demand for quality improvement}

In addition to the quality gap between domestic and foreign panels, there is still an urgent need for lightweight, weatherability and cost-effective improvement of the currently used car panels and furniture panels.

At present, the service life of the panel used in the passenger compartment is less than 8 years, and the service life of the furniture panel is 2-3 years. The polymer material and PVC veneer used have poor fire resistance rating, low strength and general density. In comparison, the aluminum honeycomb composite panel has lower density, higher specific strength, higher weatherability, more than 10 years or even decades of service life, and significantly improved fire performance. At the same time, the aluminum alloy preparation process is environmentally friendly, the product is non-toxic, tasteless, and the material can be recycled. The high strength, high hardness and low deformation characteristics of the metal material itself can significantly reduce the later maintenance cost of the material. Therefore, the material performance advantages and cost performance are significantly improved.

It will be an effective way to upgrade the materials and improve the quality of the panel for the motorhome by using the aluminum honeycomb structure composite panel with lighter weight, better weather resistance and nonflammability.

\section{Aluminum honeycomb composite}

Aluminum honeycomb composite material mainly refers to the sandwich composite structure, formed by making aluminum foil into honeycomb like structural material and bonding wood, stone and metal veneer on the upper and lower surfaces. This kind of aluminum honeycomb composite panel is equivalent to the I-beam structure, with outstanding compression and bending resistance, and the weight is only $10 \% \sim 20 \%$ of the same volume of metal panel, and has the characteristics of high specific strength, high weather resistance, fire resistance, high temperature resistance and environmental protection ${ }^{[5,6]}$. At present, hexagonal honeycomb is commonly used in aluminum honeycomb composite panel ${ }^{[6]}$.

Due to the perfect structural strength of honeycomb, people have been committed to the bionic application research of honeycomb structure for many years. Since the 1950 s, honeycomb materials have been gradually applied to the industrial field. The invention of aluminum honeycomb panel has brought revolution to the development of aviation industry. Due to the difficulties in manufacturing and processing, aluminum honeycomb panel is mainly used in high-tech and high value-added 
products such as aircraft and high-speed trains. In the field of special vehicles, it is mainly used in special parts and special high-end vehicles, and less used in ordinary civil vehicles. $^{[7-11]}$

Aluminum honeycomb structure composite panel has the advantages of fire prevention, light composite, energy absorption and shock absorption, long service life, environmental protection and recyclability, which can fully meet the needs of improving the quality of the panel of the motorhome, which provides an effective reference for the application research of the motorhome ${ }^{[7-13]}$. Table 1 lists the performance comparison between the commonly used panel and aluminum honeycomb panel in the current motorhome. Aluminum honeycomb composite panel has outstanding advantages in density, service life, weather resistance and environmental protection.

Table 1. Pperformance Comparison of Common Panel and Aluminum Honeycomb Panel for Motorhome.

\begin{tabular}{|c|c|c|c|}
\hline performance & $\begin{array}{c}\text { High } \\
\text { polymer } \\
\text { composite } \\
\text { panel for } \\
\text { carriage }\end{array}$ & $\begin{array}{c}\text { Interior } \\
\text { furniture } \\
\text { panel }\end{array}$ & $\begin{array}{c}\text { Aluminum } \\
\text { honeycomb } \\
\text { composite } \\
\text { panel }\end{array}$ \\
\hline density & $\begin{array}{c}0.2-0.6 \\
\mathrm{~g} / \mathrm{cm} 3\end{array}$ & $\begin{array}{c}0.45- \\
0.6 \mathrm{~g} / \mathrm{cm} 3\end{array}$ & $\begin{array}{c}0.1-0.4 \\
\mathrm{~g} / \mathrm{cm} 3\end{array}$ \\
\hline life & $\begin{array}{c}5-8 \text { years, } \\
\text { aging } \\
\text { easily }\end{array}$ & $\begin{array}{c}\text { Domestic } \\
2-3 \text { years, } \\
\text { imported 3- } \\
8 \text { years }\end{array}$ & $\begin{array}{c}\text { More than } 10 \\
\text { years }\end{array}$ \\
\hline combustion & combustibl & $\begin{array}{c}\text { combustibl } \\
\text { performance }\end{array}$ & $\begin{array}{c}\text { Incombustibl } \\
\text { e material }\end{array}$ \\
\hline Environmenta & strong & Odorous, \\
1 protection & smell, & not & $\begin{array}{c}\text { Non-toxic, } \\
\text { tasteless and } \\
\text { recyclable }\end{array}$ \\
\hline Wect & yielding & yielding & $\begin{array}{c}\text { No } \\
\text { deformation, } \\
\text { washable }\end{array}$ \\
\hline deformation & & & Not affected \\
\hline UV resistant & yielding & yielding & Anti \\
\hline Corrosion & Certain & yielding & corrosion, no \\
Resistance & corrosion \\
& resistanc & & \\
\hline
\end{tabular}

In terms of density, strength, weather resistance, fire resistance and environmental protection, the quality of aluminum honeycomb composite panel is obviously better than the panel material currently used in the motorhome. The application of aluminum honeycomb composite to the motorhome can further reduce the weight of the motorhome, and improve the environmental protection, light weight, fire resistance and weather resistance of the compartment panel and the interior furniture panel of the motorhome. Compared with the imported products of the same kind, the aluminum honeycomb composite has a certain cost advantage, increase service life and significantly improve cost performance.

The following are some application cases of aluminum honeycomb composite.

(1) aviation and aerospace equipment materials

In the aviation sector, aluminum honeycomb material is widely used in helicopter power cabin fairing, bomber rudder, transport aircraft floor, assault aircraft flap and civil aircraft spoiler. In the aerospace field, aluminum honeycomb materials are widely used in the internal and external components of spacecraft such as satellites.

(2) Rail vehicle

Aluminum honeycomb composite panel with adhesive structure is widely used in the door, floor and roof of rail vehicles.

(3) Civil field

At present, aluminum honeycomb composite technology has been applied in building wallpanel, floor and roof. It has excellent properties such as high wind pressure resistance, shock absorption, sound insulation, heat preservation, flame retardant and high strength. It can be used for high-end civil furniture panel and engineering decoration panel after compounding the pattern plate and aluminum honeycomb. The pattern panel can imitate a variety of marble, stone and wood patterns, and has a wide range of applications. For example, aluminum honeycomb curtain wall panel is an advanced decorative material used on the external wall of high-rise buildings in recent years. It belongs to a light and thick hollow sandwich structure, with high strength and high specific strength, and good sound and heat insulation performance.

\section{Advantages of aluminum honeycomb composite used in motorhome}

\subsection{Processing and appearance advantages}

The panel of aluminum honeycomb composite panel is generally metal panel, which is pressed by mold. The processed material has smooth and regular surface, minimal deformation, high dimensional accuracy, good texture and good painting effect. Aluminum honeycomb structure material is suitable for the forming requirements of simple shape panel material on vehicles, and its molding technology is excellent. However, most of the traditional metal panels and profiles are welded in the process of pressing or bending, which is slightly inferior to the aluminum honeycomb parts in the aspects of smoothness, deformation and dimensional accuracy. The application of aluminum honeycomb composite technology in the motorhome can improve the overall appearance quality of the panel.

\subsection{Decorative stability and weatherability}

The stability of surface decoration is mainly analyzed from the anti-aging property of the material surface. In the production process of aluminum honeycomb panel, by ensuring the thickness of the coating and using high-grade and high-quality paint or powder spraying, it can meet the requirements of surface decoration stability to keep the color unchanged. In the process of compounding the panel and the aluminum honeycomb core, the outward facing surface decoration of the panel will not be damaged.

The aluminum alloy panel of aluminum honeycomb composite panel has good antistatic adsorption property, cleanliness and cleanliness, cleanliness and abrasion resistance, and excellent UV resistance, moisture resistance and anti-aging performance. The application of aluminum honeycomb composite technology in the 
motorhome can improve the decorative stability and weatherability of the panel.

\subsection{Environmental protection and safety}

Aluminum honeycomb and aluminum panel of aluminum honeycomb composite panel are all aluminum. There is no pollution and harmful gas volatilization in the production, processing, composite and final recovery of raw materials, so the environmental performance is excellent. By using aluminum honeycomb composite panel to replace polymer materials and wood, the fireproof performance of the panel can be improved to a level, and the vehicle safety performance can be significantly improved.

\subsection{Energy saving and weight reduction}

Low density and high-strength aluminum honeycomb composite panel is used as a structural part in the motorhome. It can completely replace the external compartment panel and internal furniture panel to reduce the weight of the whole vehicle and save energy consumption.

\section{Conclusions}

When the aluminum honeycomb composite panel is applied to the motorhome, the quality of the compartment and interior furniture panel will be significantly improved, which is mainly reflected in the improvement of strength, fire performance, weatherability, environmental protection and recyclability. Therefore, the motorhome is more high-end, reliable and durable. In view of the light weight, high weather resistance and environmental protection requirements of motorhomes, aluminum honeycomb composite material, as a new type of material with mature industrialization and excellent performance, has a very good application prospect.

The use of aluminum honeycomb composite panel can reduce the use of wood and polymer materials used in the original RV, reduce the felling of trees, and the environmental pollution caused by the production and waste of polymer materials. Furthermore, the aluminum honeycomb composite panel material can be recycled with high utilization efficiency, greatly reducing the probability of fire, which is a kind of green material. In other aspects, based on the advantages of low density and high specific strength of aluminum honeycomb composite, the motorhome can achieve weight reduction, further reduce the energy consumption in the process of traveling, and reduce the air pollution of the vehicle.

\section{References}

1. China Industry Research Institute . In-depth analysis of the self-driving tourism industry and investment strategy research consulting report in 2021-2026 [R] . China: Annual research and consultation report of panorama survey and investment strategy on china industry, 2021.2.
2. Senuma T. Physical Metallurgy of Modern High Strength Steel Sheets [J]. ISIJ International. 2001, 41(6): 520-532.

3. Banhart J, Seeliger H W. Aluminium foam sandwich panels: Manufacture, metallurgy and applications[J]. Advanced Engineering Materials, 2008, 10(9): 793802.

4. Ning $\mathrm{H}$, Janowski $\mathrm{G} \mathrm{M}$, Vaidya $\mathrm{U} \mathrm{K}$, et al. Thermoplastic sandwich structure design and manufacturing for the body panel of mass transit vehicle[J]. Composite Structures, 2007, 80(1): 82-91.

5. Herrmann A S, Zahlen P C, Zuardy I. Sandwich structures technology in commercial aviation[M]. Sandwich structures 7: Advancing with sandwich structures and materials. Springer, Dordrecht, 2005: 13-26.

6. Prof, Dehankar. Implementation Of Aircraft Wardrobe Using Honeycomb Composite Over Aluminium [J] . International Journal of Innovative Science, Engineering \& Technology, Vol. 2 Issue 10, October 2015.

7. Aminanda $\mathrm{Y}$, Castanié $\mathrm{B}$, Barrau $\mathrm{J} \mathrm{J}$, et al. Experimental Analysis and Modeling of the Crushing of Honeycomb Cores. Applied Composite Materials. 2005, 12(3): 213-227.

8. Ashab A S M, Ruan D, Lu G, et al. Experimental investigation of the mechanical behavior of aluminum honeycombs under quasi-static and dynamic indentation. Materials \& Design.2015, 74: 138-149.

9. Newton J F, Martin T D, Westre W N, et al. Lightweight honeycomb panel structure: U.S. Patent 5,445,861[P]. 1995-8-29.

10. Charles E H, Starnes Jr J H, Mark J S. An assessment of the state-of-the-art in the design and manufacturing of large composite structures for aerospace vehicles[J]. 2001.

11. Metschkow B. Sandwich panels in shipbuilding[J]. Polish Maritime Research, 2006: 5-8.

12. Wang D. Impact behavior and energy absorption of paper honeycomb sandwich panels[J]. International Journal of Impact Engineering, 2009, 36(1): 110-114.

13. Chen W, Hao H. Experimental and numerical study of composite lightweight structural insulated panel with expanded polystyrene core against windborne debris impacts[J]. Materials \& Design, 2014, 60: 409-423. 